\title{
Capílulo 8
}

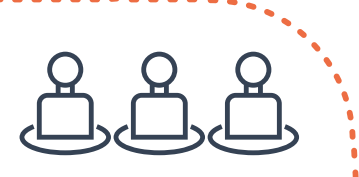

\section{Inhabilidad para contratar con el Estado por interés propio o parentesco}

P ara dar aplicación a esta inhabilidad debe tenerse en cuenta lo establecido en los artículos 35 y siguientes del Código Civil Colombiano:

"Articulo 35. Parentesco de consanguinidad. Parentesco de consanguinidad es la relación o conexión que existe entre las personas que descienden de un mismo tronco o raíz, o que están unidas por los vínculos de la sangre. (...)"

"Artículo 37. Grados de consanguinidad. Los grados de consanguinidad entre dos personas se cuentan por el número de generaciones. Así, el nieto está en segundo grado 
de consanguinidad con el abuelo, y dos primos hermanos en cuarto grado de consanguinidad entre sí. (...)"

\section{"Artículo 41. Líneas y grados del pa-} rentesco. En el parentesco de consanguinidad hay líneas y grados. Por línea se entiende la serie y orden de las personas que descienden de una raíz o tronco común."

\section{"Artículo 44. Línea colateral. La línea} colateral, transversal u oblicua, es la que forman las personas que aunque no procedan las unas de las otras, si descienden de un tronco común, por ejemplo: hermano y hermana, hijos del mismo padre y madre; sobrino y tío que proceden del mismo tronco, el abuelo."

\section{"Artículo 46. Línea transversal. En la} línea transversal se cuentan los grados por el número de generaciones desde el uno de los parientes hasta la raíz común, y desde éste hasta el otro pariente. Así, dos hermanos están en segundo grado; el tío y el sobrino en tercero, etc". 


\section{GRADOS DE PARENTESCO POR CONSANGUINIDAD Y POR AFINIDAD}

Tenga en cuenta los siguientes gráficos para efectos de establecer inhabilidades e incompatibilidades en materia de contratación estatal.

\section{Grados de parentesco}

\section{Parentesco por consanguinidad}

Padres

\section{1. er Grado}

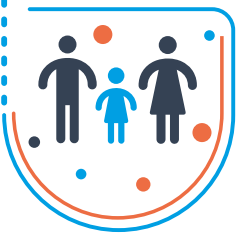

Hijos 1. ${ }^{\text {er Grado }}$

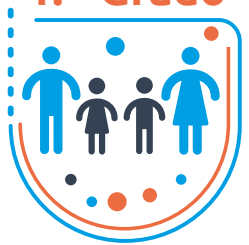

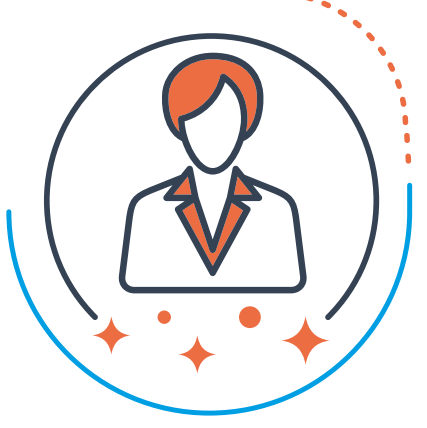

Sobrinos-

Tíos

3. er Grado

Primos

Hermanos:

$2 .{ }^{\circ} \mathrm{Grado}$
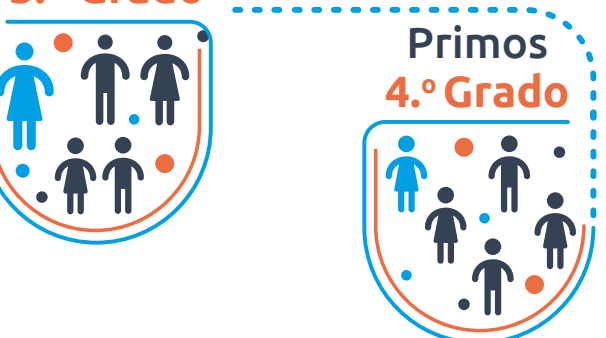


\section{Grados de parentesco Parentesco por afinidad}
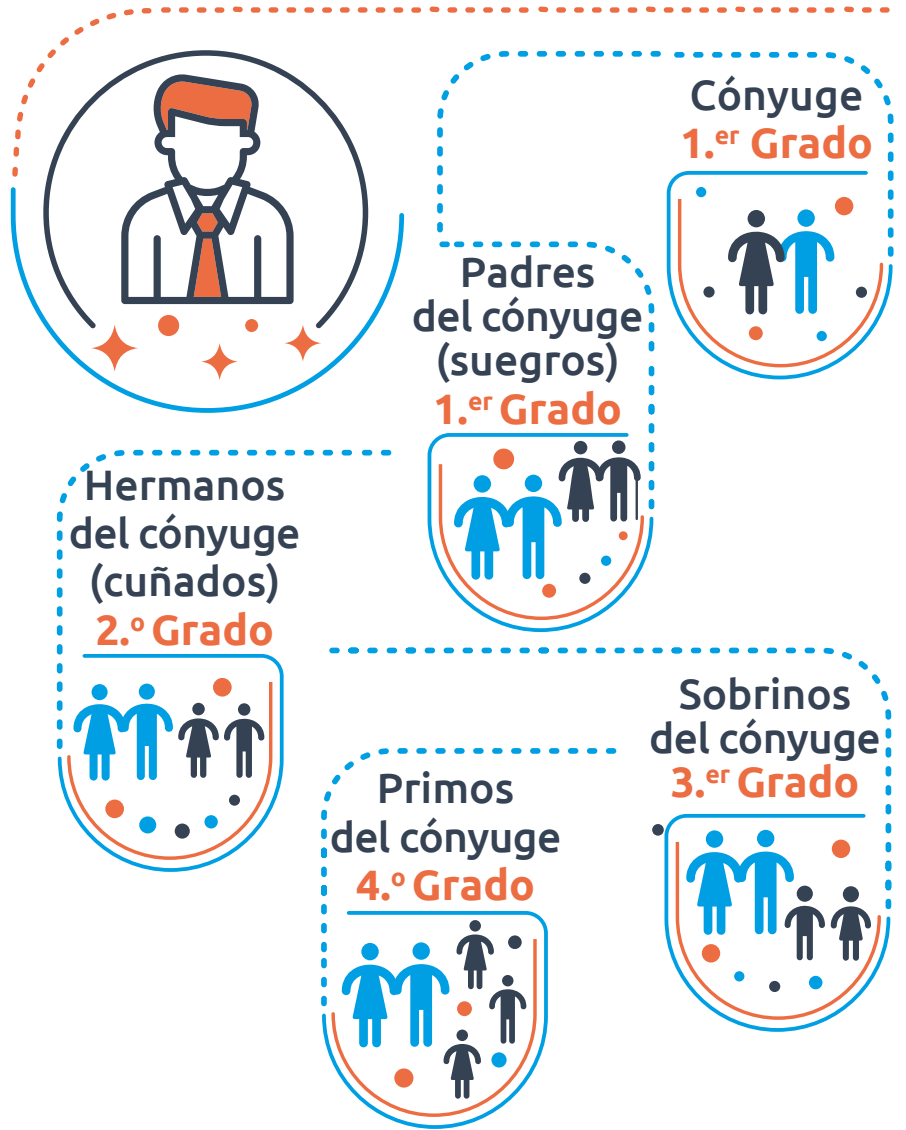
El numeral $2^{\circ}$ del artículo $8^{\circ}$ de la Ley 80 de 1993 establece las inhabilidades e incompatibilidades para contratar y particularmente indica lo siguiente en relación con aquellas que se originan por razón al parentesco:

"Artículo $8^{\circ}$ De las Inhabilidades e Incompatibilidades para Contratar:

(....).

$2^{\circ}$. Tampoco podrán participar en licitaciones o concursos ni celebrar contratos estatales con la entidad respectiva: (...)

b. Las personas que tengan vínculos de parentesco, hasta el segundo grado de consanguinidad, segundo de afinidad o primero civil con los servidores públicos de los niveles directivo, asesor ejecutivo o con los miembros de la junta o consejo directivo, o con las personas que ejerzan el control interno o fiscal de la entidad contratante. Literal declarado EXEQUIBLE por la Corte Constitucional mediante Sentencia C-429 de 1997. 
Nota 1: De conformidad con este literal, no podrán participar en licitaciones o concursos ni celebrar contratos estatales con la entidad respectiva las personas que tengan vínculos de parentesco, hasta el segundo grado de consanguinidad-padres, hijos, hermanos, abuelos, nietos-, segundo de afinidad -suegros, nueras, yernos- o primero civil-padres adoptantes e hijos adoptivos- con los servidores públicos de los niveles directivo, asesor ejecutivo o con las personas que ejerzan el control interno o fiscal de la entidad contratante. Se precisa que si llegare a sobrevenir inhabilidad o incompatibilidad en el contratista en la misma entidad donde está laborando, este cederá el contrato previa autorización escrita de la entidad contratante o, si ello no fuere posible, renunciará a su ejecución. 525354

Nota 2: Conforme a lo indicado en el artículo $1^{\circ}$ de la Ley 1148 de 2007, modificado por el artículo $1^{\circ}$ de la Ley 1296 de 2009, "Los cónyuges o compañeros permanentes de los gobernadores, diputados, alcaldes municipales y distritales, concejales municipales y distritales y sus parientes dentro del cuarto 
grado de consanguinidad; segundo de afinidad,

o primero civil no podrán ser contratistas del respectivo departamento, distrito o municipio, o de sus entidades descentralizadas, ni directa, ni indirectamente ${ }^{55 "}$. En este punto debe tenerse en cuenta que la Corte Constitucional estudio la Constitucionalidad de este artículo y "en lo que concierne al resto del inciso demandado, cuyo texto es "los cónyuges o compañeros permanentes de los gobernadores, diputados, alcaldes municipales y distritales y concejales municipales y distritales, y sus parientes no podrán ser designados funcionarios del respectivo departamento, distrito o municipio, o de sus entidades descentralizadas", indicó que es evidente que contraría el Art. 292, inciso $2^{\circ}$, de la Constitución, ya que la prohibición allí contenida no tendría un límite por razón de los grados de parentesco. Por tanto, la Corte lo declaró exequible en forma condicionada, en el entendido de que la prohibición se predica de los parientes en el segundo grado de consanguinidad, primero de afinidad y único civil, como lo establece dicha norma superior." ${ }^{\prime 56}$ Así las cosas, conforme al inciso $3^{\circ}$ del artículo 49 de la Ley 617 de 2000, modificado por el artí- 
culo 1 de la Ley 1296 de 2009, los cónyuges o compañeros permanentes de los diputados, y sus parientes dentro del cuarto grado de consanguinidad (padres, hijos, hermanos, nietos, abuelos, tíos, sobrinos y primos), segundo de afinidad, o primero civil no podrán ser contratistas del respectivo departamento ${ }^{57}$.
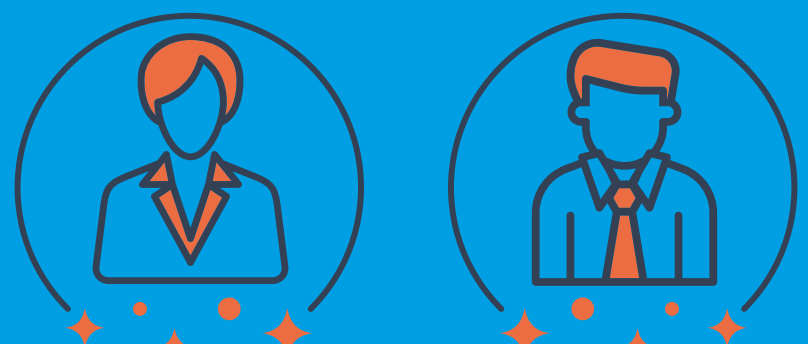

c. El cónyuge compañero o compañera permanente del servidor público en los niveles directivo, asesor, ejecutivo, o de un miembro de la junta o consejo directivo, o de quien ejerza funciones de control interno o de control fiscal. El texto subrayado fue declarado EXEQUIBLE por la Corte Constitucional mediante Sentencia C-029 de 2009, en el entendido de que en igualdad de condiciones, ellas comprenden también a los integrantes de las parejas de un mismo sexo. 
Nota 1: De acuerdo con lo dispuesto en los literales b) y c) del numeral segundo del artículo 8 de la Ley 80 de 1993 no podrán contratar con la respectiva entidad pública los cónyuges o compañeros permanentes ni las personas que tengan vínculos de parentesco hasta el segundo grado de consanguinidad (padres, hijos, hermanos, abuelos y nietos), segundo de afinidad (suegros, cuñados, yerno y nuera) o primero civil (padre adoptante, hijo adoptivo) con los servidores públicos de los niveles directivo, asesor, ejecutivo ${ }^{58}$.

\section{Nota 2: Para efectos de determinar cuáles} son los servidores públicos que pertenecen al nivel directivo, debe tenerse en cuenta el Decreto 785 de 2005 "por el cual se establece el sistema de nomenclatura y clasificación y de funciones y requisitos generales de los empleos de las entidades territoriales que se regulan por las disposiciones de la Ley 909 de 2004". Conforme a las normas antes mencionadas, los secretarios del despacho pertenecen al nivel directivo, es decir, que una persona que tengan vínculos de parentesco hasta el segundo grado de consanguinidad con un secretario de despacho 
(nivel directivo) se encuentra inhabilitada рага contratar con la respectiva entidad territorial ${ }^{59}$.

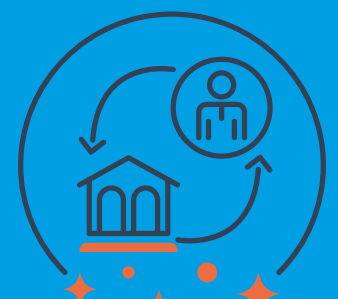

d) Las corporaciones, asociaciones, fundaciones y las sociedades anónimas que no tengan el carácter de abiertas, así como las sociedades de responsabilidad limitada y las demás sociedades de personas en las que el servidor público en los niveles directivo, asesor o ejecutivo, o el miembro de la junta o consejo directivo, o el cónyuge, compañero o compañera permanente o los parientes hasta el segundo grado de consanguinidad, afinidad o civil de cualquiera de ello, tenga participación o desempeñe cargos de dirección o manejo. El texto subrayado fue declarado EXEQUIBLE por la Corte Constitucional mediante Sentencia C-029 de 2009, en el entendido de que en igualdad de condiciones, ellas comprenden también a los integrantes de las parejas de un mismo sexo". 


\section{Notas al pie}

52. Concepto DAFP. 18841. Fecha: 28 de enero de 2019.

53. Concepto DAFP. 84551. Fecha: 15 de marzo de 2019.

54. Concepto DAFP 85161. Fecha: 18 de marzo de 2019.

55. Concepto DAFP 75801. Fecha: 11 de marzo de 2019.

56. Sentencia Corte Constitucional C-903 de 2008.

57. Concepto DAFP. 84661. Fecha: 18 de marzo de 2019.

58. Concepto DAFP. 40751. 12 de febrero de 2019.

59. Concepto DAFP. 40751. 12 de febrero de 2019. 